\title{
Effects of monomethoxypolyethylene glycol-chitosan nanoparticle-mediated dual silencing of livin and survivin genes in prostate cancer PC-3M cells
}

\author{
A.Q. Yang1, P.J. Wang ${ }^{1}$, T. Huang', W.L. Zhou' ${ }^{1}$ and J. Landman ${ }^{2}$ \\ 'Department of Urology, Ruijin Hospital Luwan Branch of Jiaotong University, \\ Shanghai, China \\ ${ }^{2}$ Department of Urology, UCI Medical Center, Orange, CA, USA \\ Corresponding author: J. Landman \\ E-mail: landmanjdu@yeah.net
}

Genet. Mol. Res. 15 (2): gmr.15027430

Received August 12, 2015

Accepted November 19, 2015

Published April 4, 2016

DOI http://dx.doi.org/10.4238/gmr.15027430

ABSTRACT. Monomethoxypolyethylene glycol-chitosan (mPEG-CS) nanoparticles were used as interfering RNA carriers to transfect human prostate cancer PC-3M cells to evaluate the effects of livin and survivin gene silencing on the proliferation and apoptosis. MPEG-CS nanoparticles with sizes of approximately $60 \mathrm{~nm}$ were first synthesized by ionic crosslinking. Through electrostatic adsorption, mPEG-CS-livin short hairpin RNA (shRNA), mPEG-CS-survivin shRNA, and mPEG-CS-(livin shRNA + survivin shRNA) nanoparticles were then prepared to transfect PC-3M cells. The mRNA and protein expression levels of livin and survivin were measured by reverse transcription-PCR and western blotting, respectively. The inhibitory effects of down-regulated livin and survivin gene expression on the cell proliferation were evaluated by MTT assay. Cell apoptosis was assessed visually using Hoechst staining. Livin and survivin expression levels in all shRNA interference groups were effectively down-regulated at both the mRNA and protein levels. Dual silencing of livin and survivin 
genes markedly inhibited cell proliferation and facilitated apoptosis, with better outcomes than those of individual shRNA treatments. mPEGCS nanoparticle-mediated dual shRNA interference of livin and survivin genes significantly reduced the expression levels in PC-3M cells, inhibited proliferation, and promoted apoptosis. As these effects were superior to single interference, this method may have synergistic effects.

Key words: Nanoparticle; Prostate cancer; PC-3M; Livin; Survivin; RNA interference

\section{INTRODUCTION}

Prostate cancer is one of the most common malignant tumors endangering males, and has been tentatively treated with biotherapies in recent years. High expression of anti-apoptotic genes in the tissues of malignant tumors has been demonstrated to be closely related with their occurrence, progression, metastasis, and prognosis (Sarela et al., 2000). Livin and survivin, which are newly identified members of the anti-apoptotic protein family, are highly expressed in tumor tissues, but not in normal differentiated tissues. These proteins have also been found to be associated with cancer onset, progression, anti-apoptosis, as well as resistance to radiotherapy and chemotherapy.

RNA interference (RNAi) technology has been widely employed to analyze gene functions because of its high efficiency and specificity (Hannon, 2002). As novel DNA carriers, nanoparticles are able to mediate the entrance of exogenous genes to cells that maintain high expression, and have thus been spotlighted in current cancer gene therapy.

In the current study, human prostate cancer PC-3M cells were transfected with livin and survivin short hairpin RNAs (shRNAs) via nanoparticle targeting to observe the influence of their mRNA and protein expressions together on cell apoptosis. Additionally, the relationship between livin, survivin, and apoptosis was explored. Our overall aim was to determine if the induction of apoptosis of prostate cancer cells by dual gene silencing is feasible and effective, and if livin and survivin may function as molecular targets in prostate cancer therapy.

\section{MATERIAL AND METHODS}

\section{Main reagents}

Sodium tripolyphosphate (TPP) was purchased from ChengDu KeLong Chemical Co., Ltd. (Chengdu, China). Chitosan (CS) (degree of deacetylation: $>90.0 \%$ ) was purchased from Shanghai Bo'ao Biological Technology Co., Ltd. (Shanghai, China). Monomethoxypolyethylene glycol (mPEG) 5000 was purchased from Sigma-Aldrich (St. Louis, MO, USA). Dulbecco's modified Eagle's medium (DMEM) was purchased from Nanjing KeyGen Biotech Co., Ltd. (Nanjing, China). Fetal bovine serum (FBS) was purchased from Hangzhou Sijiqing Biological Engineering Materials Co., Ltd. (Hangzhou, China). TRIzol Reagent was bought from Life Technologies (Carlsbad, CA, USA). Reverse transcription (RT)-PCR kit was purchased from TaKaRa (Shiga, Japan). Trypsin and MTT were purchased from Roche (Basel, Switzerland). Cell lysis buffer and Hoechst staining kit were purchased from Beyotime Institute of Biotechnology (Jiangsu, China). Rabbit anti-human livin 
and survivin antibodies, rabbit anti-human GAPDH polyclonal antibody, horseradish peroxidase(HRP) labeled goat anti-rabbit lgG, and Western blot DAB color development kit were purchased from Santa Cruz (Santa Cruz, CA, USA).

\section{Cell culture}

The human prostate cancer cell line PC-3M was purchased from the cell preservation center of Wuhan University. PC-3M cells were cultured in DMEM supplemented with $10 \%$ FBS and $100 \mathrm{U} / \mathrm{mL}$ streptomycin-penicillin. The cells were routinely incubated in a $5 \% \mathrm{CO}_{2}$ atmosphere at $37^{\circ} \mathrm{C}$, passaged following $0.25 \%$ trypsin digestion, and cells growing logarithmically were selected for experimentation.

\section{Preparation of livin and survivin shRNA plasmids}

The identification numbers for livin and survivin in the National Center for Biotechnology Information (NCBI) GenBank database were NM-022161 and NM-001168, respectively. Based on the NCBI sequences, shRNA plasmids against livin and survivin were designed, synthesized, and sequenced by Obio Technology Co., Ltd. (Shanghai, China).

\section{Synthesis of mPEG-CS nanoparticles}

mPEG-CS nanoparticles were synthesized through ionic crosslinking according to published methods (Kulkarni et al., 2006). Briefly, $50 \mathrm{mg} \mathrm{CS}$ was added to $100 \mathrm{~mL} 1 \%$ acetic acid (V/V) and magnetically stirred for $30 \mathrm{~min}$ until the CS was completely dissolved. Then, $1 \mathrm{~mL} 1 \% \mathrm{mPEG}$ solution (V/V) was added, and the mixture was stirred for $2 \mathrm{~h}$ to give an mPEG-CS solution. Subsequently, $1 \mathrm{mg} / \mathrm{mL}$ TPP solution was slowly added with stirring until there was a visible opalescence, which was thereafter stirred at room temperature overnight to form the nanoparticle suspension. The nanoparticle suspension was then centrifuged for $10 \mathrm{~min}$ at 16,000 rpm, washed twice and dispersed ultrasonically in sterile double-distilled water, and finally stored at $4^{\circ} \mathrm{C}$ until use.

\section{Synthesis of nanoparticles carrying shRNA-encoding genes}

Nanoparticles carrying livin and survivin shRNA-encoding genes were synthesized with electrostatic adsorption as previously described (Chen et al., 2007). Solutions (2.5 $\mu \mathrm{L}$ each, 0.35 $\mathrm{mg} / \mathrm{mL}$ ) of recombinant livin and survivin shRNA plasmids (5 $\mu \mathrm{L}$ total) were mixed with $15 \mu \mathrm{L}$ mPEG-CS nanoparticle solution, reacted in a $5^{\circ} \mathrm{C}$ water bath for $20 \mathrm{~min}$, and vortexed for 30 min, which yielded an mPEG-CS-(livin shRNA + survivin shRNA) nanoparticle suspension. Then, mPEG-CS-livin and mPEG-CS-survivin shRNA nanoparticle suspensions were prepared by using $5 \mu \mathrm{L}$ recombinant livin and $5 \mu \mathrm{L}$ recombinant survivin with the same method, respectively.

\section{Cell grouping and transfection}

PC-3M cells growing logarithmically were seeded onto 6-well plates at a density of $2 \times 10^{5}$ well 1 day before transfection, and cultured in double-antibiotic treated and serum-free DMEM in a $5 \% \mathrm{CO}_{2}$ atmosphere at $37^{\circ} \mathrm{C}$. When cells reached $80 \%$ confluency, they were divided into the following four transfection groups: 1) a livin + survivin interference group, which was transfected 
with mPEG-CS-(livin shRNA + survivin shRNA) nanoparticles; 2) a livin interference group, which was transfected only with mPEG-CS-livin shRNA nanoparticles; 3) a survivin interference group, which was transfected only with mPEG-CS-survivin shRNA nanoparticles; and 4) a negative control group, into which mPEG-CS-blank plasmid nanoparticles were added. The transfected cells were then cultured in complete DMEM for 24-72 $\mathrm{h}$.

\section{Detection of livin and survivin mRNA expression by RT-PCR}

The culture medium was discarded $48 \mathrm{~h}$ after transfection, and $1 \mathrm{~mL}$ TRIzol reagent was added to each well to extract total DNA according to manufacturer instructions. The following primers were used for RT-PCR: upstream primer of livin: 5'-TGAGGAGTTGCGTCTGGC-3'; downstream primer of livin: 5'-GCACGGCACAAAGACGAT-3' (length of amplified livin fragment: 492 bp); upstream primer of survivin: 5'-CTTTCTCAAGGACCACCGCATCT-3', downstream primer of survivin: 5'-GCACTTTCTCCGCAGTTTCCTC-3' (length of amplified fragment: 359 bp); upstream primer of GAPDH (internal reference): 5'-ACCACAGTCCATGCCATCAC-3'; and downstream primer of GAPDH: 5'-TGCTGTAGCCAAATTCGTTG-3' (length of amplified fragment: $450 \mathrm{bp}$ ). RT-PCR was carried out with the following settings: reverse transcription at $50^{\circ} \mathrm{C}$ for 30 min; cycling at $95^{\circ} \mathrm{C}$ for $15 \mathrm{~min} ; 30$ cycles of denaturation at $94^{\circ} \mathrm{C}$ for $30 \mathrm{~s}$, annealing at $57^{\circ} \mathrm{C}$ for $30 \mathrm{~s}$, extension at $72^{\circ} \mathrm{C}$ for $30 \mathrm{~s}$; and a final extension at $72^{\circ} \mathrm{C}$ for $10 \mathrm{~min}$. The PCR products were resolved by agarose gel electrophoresis.

\section{Detection of livin and survivin protein expression by western blotting}

The culture medium was discarded $48 \mathrm{~h}$ after transfection, and the cells were washed twice with cold PBS. The cells were then lysed by adding $150 \mu \mathrm{L}$ pre-cooled lysis buffer per well at $4^{\circ} \mathrm{C}$ for $30 \mathrm{~min}$, and the lysates were then centrifuged at $12,000 \mathrm{rpm}$ for $15 \mathrm{~min}$ at $4^{\circ} \mathrm{C}$ to remove nonsoluble lipids. Afterwards, the supernatants were collected and the proteins were quantified. The proteins were then resolved via sodium dodecyl sulfate-polyacrylamide gel electrophoresis under denaturing conditions. The proteins were subsequently electronically transferred onto nitrocellulose membranes. The membranes were then blocked for $4 \mathrm{~h}$ at room temperature, incubated overnight with primary antibodies against livin, survivin, and $\beta$-actin (loading control) at $4^{\circ} \mathrm{C}$, washed three times with PBS, incubated with secondary HRP-conjugated antibodies for $2 \mathrm{~h}$ at room temperature, and washed three times again with PBS. DAB reagent was then added for band development and visualization. After grayscale scanning of the membranes and image analysis to determine band intensities, relative protein expression levels were evaluated as the ratios of the band intensities of livin/ $\beta$-actin and survivin/ $\beta$-actin.

\section{Detection of inhibitory effects of RNAi on PC-3M cell proliferation by MTT assay}

After transfection, the cells were cultured for 24,48 , or $72 \mathrm{~h}$. MTT solution $(5 \mathrm{mg} / \mathrm{mL}, 10 \mu \mathrm{L})$ was then added to each well followed by a $4-\mathrm{h}$ incubation at $37^{\circ} \mathrm{C}$. Subsequently, the culture medium was carefully discarded and $10 \mu \mathrm{L}$ DMSO was added to each well. Then, the plates were shaken for 10 min at constant temperature. Absorbance (A) of each well at $490 \mathrm{~nm}$ was measured with an automatic microplate reader. The inhibitor rate percentage of tumor cells was calculated as ( 1 - $A_{\text {experimental group }}$ ' $\left.A_{\text {blank control group }}\right) \times 100 \%$. The data of each group are reported as means \pm standard deviation (SD). 


\section{Effects of RNAi on PC-3M cell apoptosis detected by Hoechst staining}

The cells were transferred to the microscope slide after $48 \mathrm{~h}$. The cells were fixed $48 \mathrm{~h}$ after transfection by adding a fixing solution according to the Hoechst staining kit instructions. After the fixing solution was removed, the cells were Hoechst stained on a shaker for $5 \mathrm{~min}$ at room temperature. After removal of the staining solution, the microscope slides were covered with a coverslip and sealed with antifade solution. The morphology of the cells was observed under an inverted fluorescence microscope and photographed. Cells from each well were counted in five randomly selecting fields of view. The apoptotic index (Al) was calculated as the number of apoptotic cells / (number of normal cells + number of apoptotic cells) $\times 100 \%$. The data of each group are reported as means \pm SD.

\section{Statistical analysis}

All data were analyzed by the SPSS 17.0 software (SPSS Inc. Chicago, IL, USA). Differences in livin and survivin mRNA expressions between PC-3M cell groups were compared by univariate analysis of variance. Pairwise comparisons were conducted with the LSD test. Differences in livin and survivin protein expressions between PC-3M cell groups, and the effects of RNAi on survival and apoptosis were evaluated by the $\mathrm{K}-\mathrm{wH}$ rank-sum test. Pairwise comparisons were performed with the Bonferroni method. Differences were considered statistically significant when $P$ values were less than 0.05 .

\section{RESULTS}

\section{Morphologies of mPEG-CS, mPEG-CS-livin shRNA, and mPEG-CS-survivin shRNA nanoparticles}

As shown in the transmission electron microscopy images of mPEG-CS-livin and mPEGCS-survivin shRNA nanoparticles, they are evenly distributed uniformly in approximate spheres with diameters of approximately $100 \mathrm{~nm}$, and without apparent agglomeration (Figures 1 and 2).

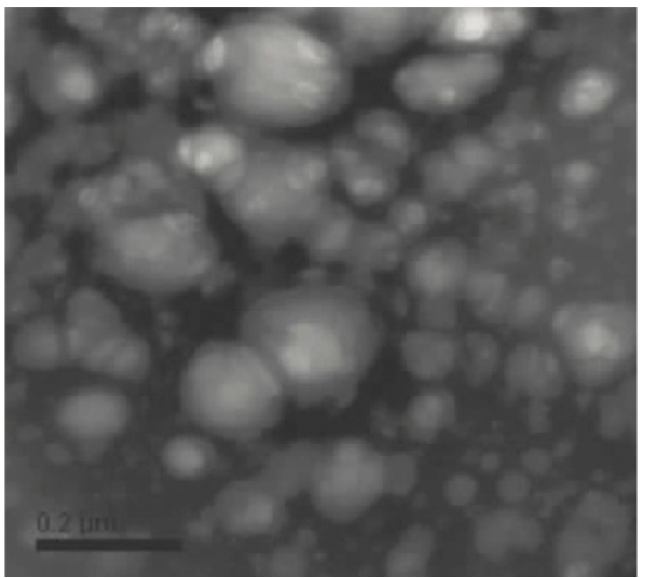

Figure 1. Transmission electron microscopy image of mPEG-CS-livin shRNA nanoparticles. Bar $=200 \mathrm{~nm}$. 


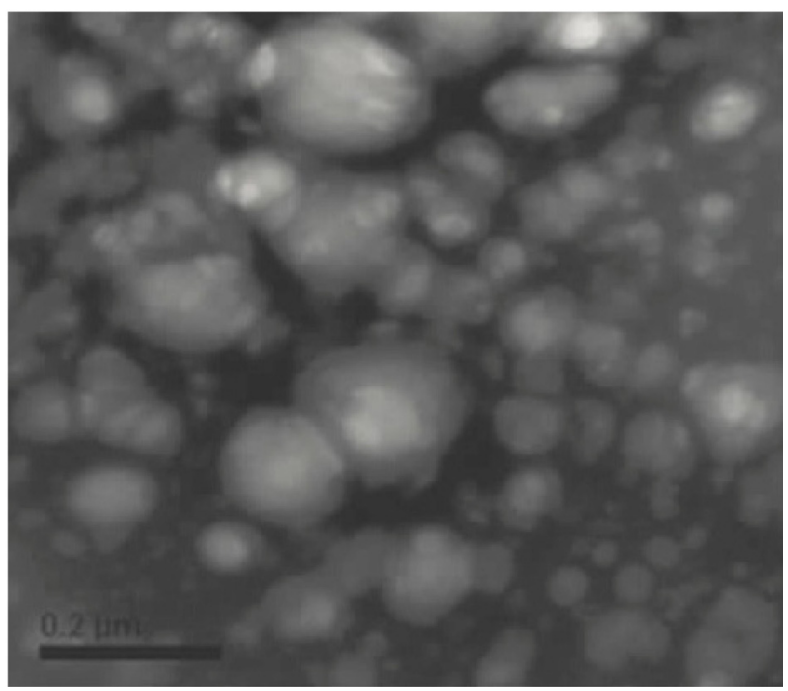

Figure 2. Transmission electron microscopy image of mPEG-CS-survivin shRNA nanoparticles. Bar $=200 \mathrm{~nm}$.

\section{RT-PCR results of livin and survivin mRNA expression following RNAi}

As shown in Figure 3, livin and livin + survivin interference significantly inhibited the expression of livin mRNA compared with that of the negative control group $(P<0.05)$. Similarly, the expression of survivin mRNA was significantly suppressed in survivin and livin + survivin interference groups compared to that of the negative control group $(P<0.05)$ (Figure 4).

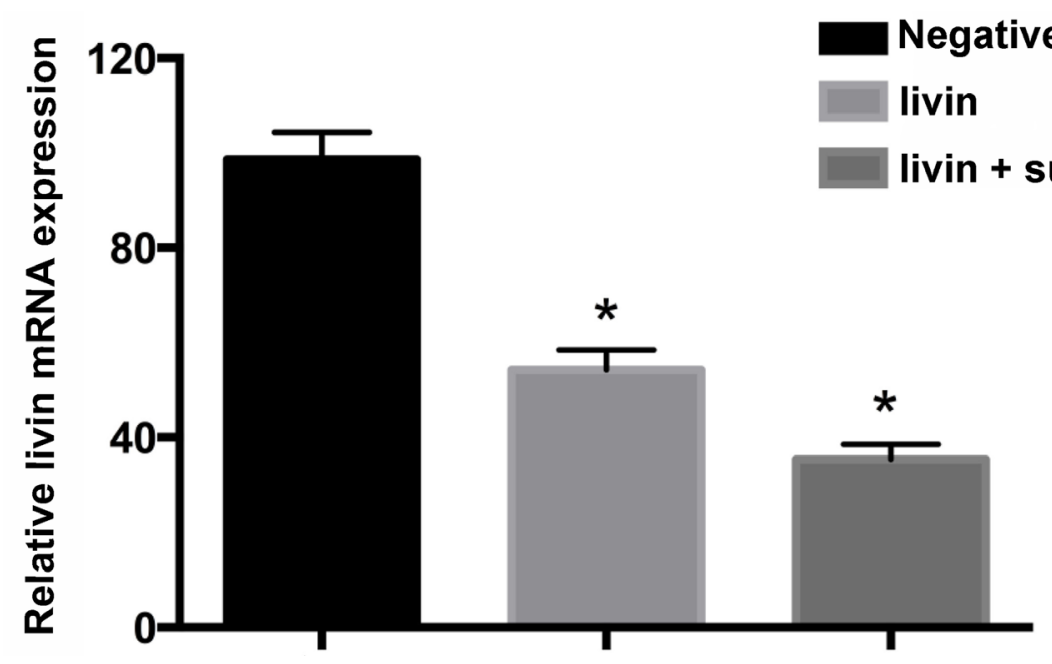

Figure 3. Effects of RNAi on livin mRNA expression in PC-3M cells. ${ }^{*} \mathrm{P}<0.05$, compared with the negative control group. 


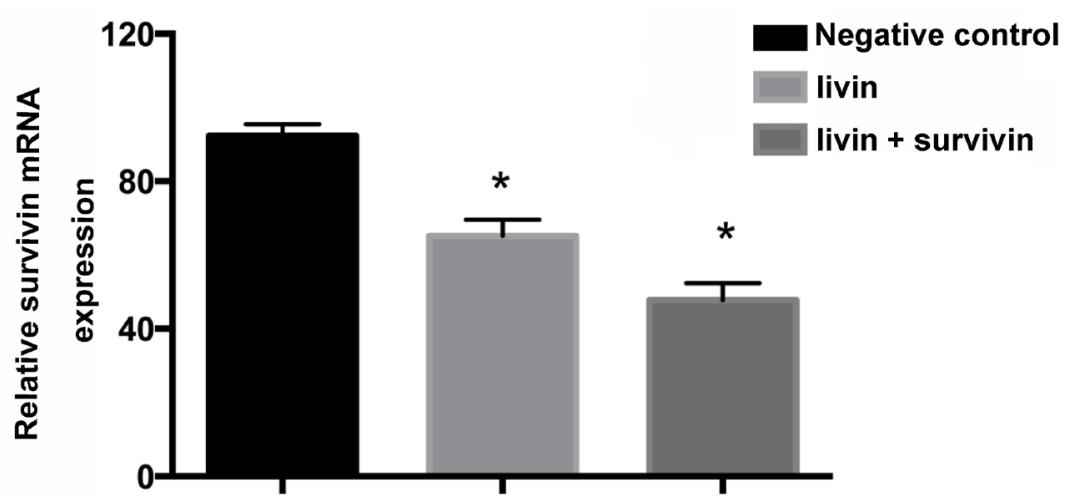

Figure 4. Effects of RNAi on survivin mRNA expression in PC-3M cells. ${ }^{*} \mathrm{P}<0.05$, compared with the negative control group.

\section{Western blot results of livin and survivin protein expression following RNAi}

The effects of different shRNA interference on livin and survivin protein expression were evaluated by western blotting. The relative expression levels of livin protein in the negative control group, livin interference group, and livin + survivin interference group were $95.78 \pm 3.45,43.67$ \pm 4.21 , and $35.65 \pm 4.23 \%$, respectively (Figure 5). The livin protein expression levels in the two interference groups were significantly down-regulated compared with those of the negative control group $(P<0.05)$. Figure 6 shows that the relative expression levels of survivin protein in the negative control group, survivin interference group, and livin + survivin interference group were $94.51 \pm 3.23,53.82 \pm 5.27$, and $45.76 \pm 3.43 \%$, respectively. Similarly, the survivin protein expression levels in the two interference groups were significantly down-regulated compared with those of the negative control group $(P<0.05)$.

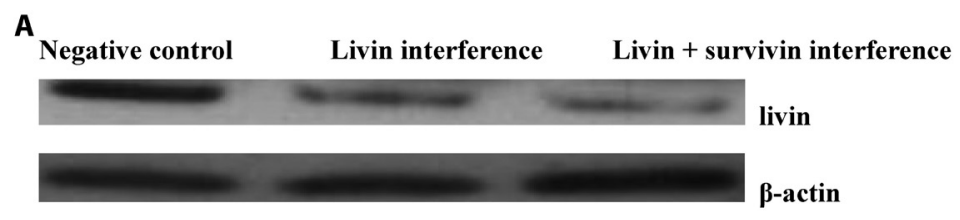

B

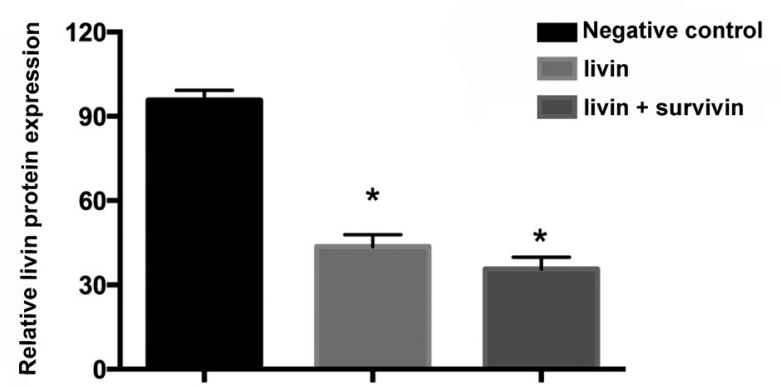

Figure 5. Western blot results of livin protein expression inhibited by RNAi. A. western blot results; B. relative band intensities, ${ }^{*} \mathrm{P}<0.05$, compared with the negative control group. 
A

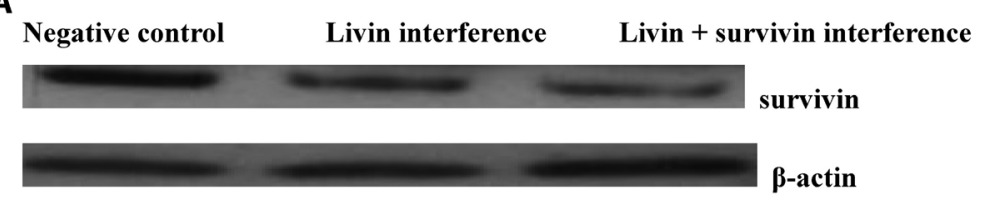

B

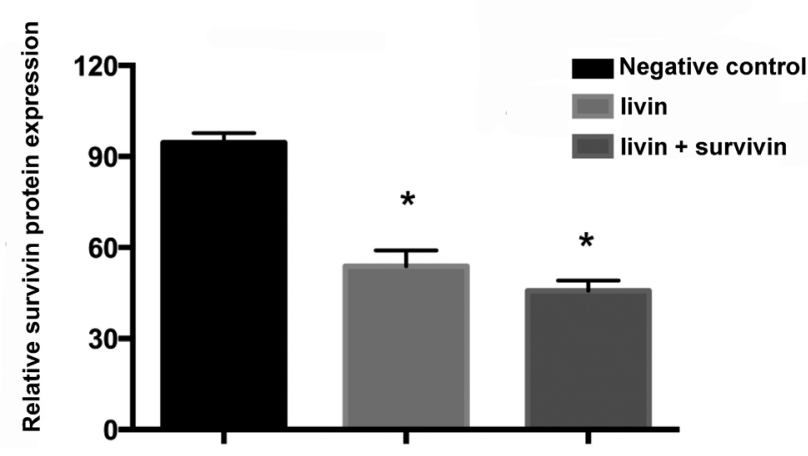

Figure 6. Western blot results of survivin protein expression inhibited by RNAi. A. Western blot results; B. relative band intensities, ${ }^{*} P<0.05$, compared with the negative control group.

\section{MTT assay results for PC-3M cell proliferation following RNAi}

The inhibitory effects of RNAi on PC-3M cell proliferation were evaluated by MTT assay. Livin + survivin, livin, and survivin shRNA interference inhibited the proliferation of PC-3M cells more than that of the negative control group, and the effects were enhanced significantly with extended time $(P<0.05)$. Additionally, dual livin + survivin interference was significantly superior to individual treatments in inhibiting $P C-3 M$ cell proliferation $(P<0.05)$ (Table 1).

Table 1. Inhibition rate percentages of different interference groups (\%) (means \pm SD).

\begin{tabular}{|c|c|c|c|}
\hline Experimental group & $24 \mathrm{~h}$ & $48 \mathrm{~h}$ & $72 \mathrm{~h}$ \\
\hline Livin interference* $^{*}$ & $34.43 \pm 2.13$ & $43.67 \pm 3.68$ & $48.12 \pm 1.61$ \\
\hline Survivin interference ${ }^{\star}$ & $32.67 \pm 1.68$ & $41.64 \pm 3.37$ & $47.76 \pm 1.96$ \\
\hline Livin + survivin interference ${ }^{\star \#}$ & $53.43 \pm 2.41$ & $57.34 \pm 0.87$ & $61.22 \pm 4.12$ \\
\hline Negative control & $2.27 \pm 1.54$ & $3.45 \pm 1.14$ & $5.41 \pm 1.44$ \\
\hline
\end{tabular}

${ }^{*} \mathrm{P}<0.05$ vs negative control group, ${ }^{\#} \mathrm{P}<0.05$ vs livin and survivin interference groups.

\section{Changes in PC-3M cell apoptosis following RNAi}

The apoptosis of PC-3M cells subjected to Hoechst staining was visually evaluated under a fluorescence microscope. Normal cell nuclei were stained blue, while apoptotic cells were scattered, stained densely, and were pale. The Als of the negative control, livin interference, survivin interference, and livin + survivin interference groups were $5.74 \pm 1.14,34.56 \pm 3.14$, $28.54 \pm 5.13$, and $55.38 \pm 1.37 \%$, respectively. The values of the three interference groups were significantly higher than those of the negative control group $(P<0.05)$. Moreover, dual livin + survivin interference induced the apoptosis of $\mathrm{PC}-3 \mathrm{M}$ cells more than that of the single treatments groups $(P<0.05)$ (Figure 7$)$. 


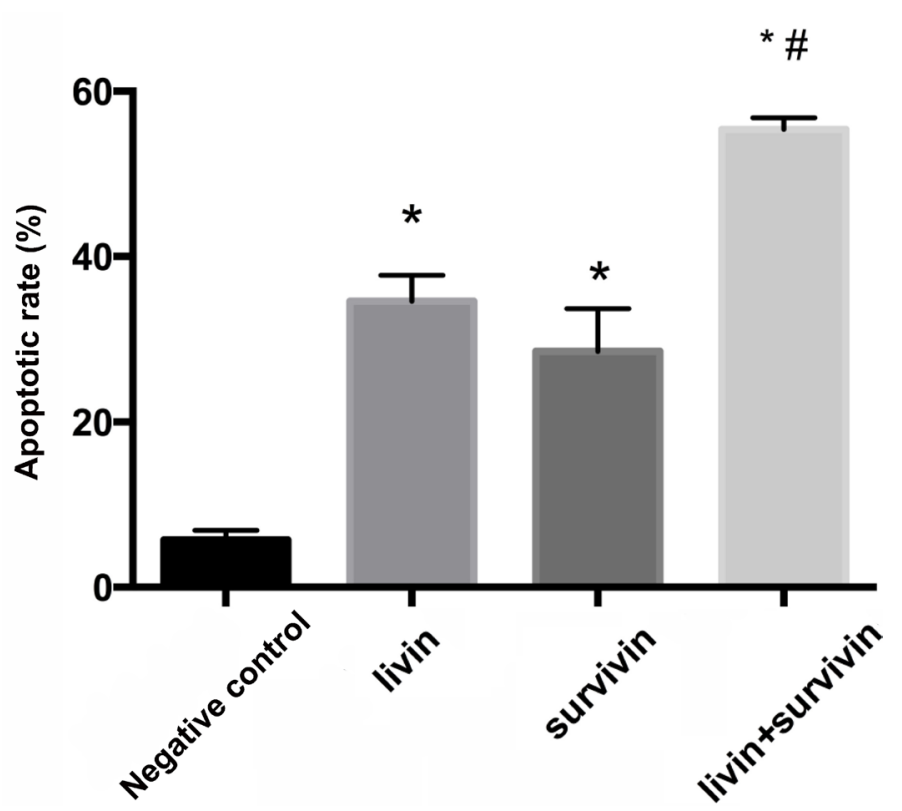

Figure 7. Effects of RNAi on PC-3M cell apoptosis (\%). ${ }^{*} \mathrm{P}<0.05$ vs the negative control group, ${ }^{\#} \mathrm{P}<0.05$ vs livin and survivin interference groups.

\section{DISCUSSION}

Survivin is the strongest anti-apoptotic member of the inhibitors of apoptosis protein (IAP) family, and its 142 amino acids are encoded by the 14.7-kb BIRC5 gene. Survivin blocks cell apoptosis mainly by directly inhibiting the activities of caspase 3 and caspase 7 , by releasing the inhibitory effect of SMAC/Diablo on XIAP, and by suppressing the anti-apoptotic action of p53 (Sah et al., 2006). Livin is also an IAP family member, and its CDNA includes the isomers livin $\alpha$ and livin $\beta$ that are 897 and 843 bp long, respectively. Similar to survivin, livin inhibits tumor cell apoptosis by suppressing the activities of caspase 3 and caspase 9 , as well as by relieving the inhibitory effect of SMAC/Diablo on XIAP (Liu et al., 2007). Notably, livin and survivin are specifically and highly expressed in tumor tissues (i.e., those in prostate cancer), and not in normal maturely differentiated tissues (Mita et al., 2008; Wang et al., 2008; Yan, 2011). Therefore, livin and survivin are closely associated with tumor onset, progression, anti-apoptosis, drug resistance, and prognosis. As such, dual livin and survivin shRNA interference may promote tumor cell apoptosis more effectively than individual targeting.

Compared with traditional carriers (e.g., plasmids), surface-modifiable nanoparticles have large surface areas and high adsorptive capacity, and also allow for passive cell targeting. In the current study, we used CS, a polysaccharide derived from marine organisms, as it is highly biocompatible, safe, nontoxic, and degradable (Erbacher et al., 1998). Positively charged CS forms a polyelectrolyte complex by reacting with negatively charged DNA, thereby preventing degradation by DNases (Richardson et al., 1999). Nevertheless, since CS has poor solubility in water and common organic solvents, its application in the biomedical field has been rather limited (Kievit et al., 2009). Therefore, CS was chemically modified herein by mPEG. Low toxicity mPEG- 
CS nanoparticles have suitable sizes for gene delivery, gene-protecting effects, long circulation time, as well as high encapsulation efficiency for drug loading.

To explore the effects of livin and survivin on PC-3M cells and the applicability of mPEGCS nanoparticles in tumor treatment, mPEG-CS-livin shRNA, mPEG-CS-survivin shRNA, and mPEG-CS-(livin shRNA + survivin shRNA) nanoparticles were prepared for delivery of shRNA to these cells, which markedly inhibited livin and survivin expression at both the mRNA and protein levels. Hence, plasmids may be replaceable with the mPEG-CS nanoparticles described herein to mediate exogenous transfection of DNA.

Furthermore, the expression of livin and survivin were down-regulated in PC-3M cells, which resulted in significant inhibition of proliferation and enhanced apoptosis. Dual livin and survivin interference, as we expected, exerted more significant effects on prostate cancer cells than single treatments. In conclusion, the anti-apoptotic genes livin and survivin are involved in the onset and progression of prostate cancer, and dual inhibition of their expression may be an efficacious avenue for future gene therapies.

\section{Conflicts of interest}

The authors declare no conflict of interest.

\section{ACKNOWLEDGMENTS}

We thank all the coauthors for their cooperation.

\section{REFERENCES}

Chen J, Tian B, Yin X, Zhang Y, et al. (2007). Preparation, characterization and transfection efficiency of cationic PEGylated PLA nanoparticles as gene delivery systems. J. Biotechnol. 130: 107-113. http://dx.doi.org/10.1016/j.jbiotec.2007.02.007

Erbacher P, Zou S, Bettinger T, Steffan AM, et al. (1998). Chitosan-based vector/DNA complexes for gene delivery: biophysical characteristics and transfection ability. Pharm. Res. 15: 1332-1339. http://dx.doi.org/10.1023/A:1011981000671

Hannon GJ (2002). RNA interference. Nature 418: 244-251. http://dx.doi.org/10.1038/418244a

Kievit FM, Veiseh O, Bhattarai N, Fang C, et al. (2009). PEI-PEG-Chitosan Copolymer Coated Iron Oxide Nanoparticles for Safe Gene Delivery: synthesis, complexation, and transfection. Adv. Funct. Mater. 19: 2244-2251. http://dx.doi. org/10.1002/adfm.200801844

Kulkarni AR, Lin YH, Liang HF, Chang WC, et al. (2006). A novel method for the preparation of nanoaggregates of methoxy polyethyleneglycol linked chitosan. J. Nanosci. Nanotechnol. 6: 2867-2873. http://dx.doi.org/10.1166/jnn.2006.415

Liu B, Han M, Wen JK and Wang L (2007). Livin/ML-IAP as a new target for cancer treatment. Cancer Lett. 250: 168-176. http:// dx.doi.org/10.1016/i.canlet.2006.09.024

Mita AC, Mita MM, Nawrocki ST and Giles FJ (2008). Survivin: key regulator of mitosis and apoptosis and novel target for cancer therapeutics. Clin. Cancer Res. 14: 5000-5005. http://dx.doi.org/10.1158/1078-0432.CCR-08-0746

Richardson SC, Kolbe HV and Duncan R (1999). Potential of low molecular mass chitosan as a DNA delivery system: biocompatibility, body distribution and ability to complex and protect DNA. Int. J. Pharm. 178: 231-243. http://dx.doi. org/10.1016/S0378-5173(98)00378-0

Sah NK, Khan Z, Khan GJ and Bisen PS (2006). Structural, functional and therapeutic biology of survivin. Cancer Lett. 244: 164-171. http://dx.doi.org/10.1016/j.canlet.2006.03.007

Sarela Al, Macadam RC, Farmery SM, Markham AF, et al. (2000). Expression of the antiapoptosis gene, survivin, predicts death from recurrent colorectal carcinoma. Gut 46: 645-650. http://dx.doi.org/10.1136/gut.46.5.645

Wang L, Zhang Q, Liu B, Han M, et al. (2008). Challenge and promise: roles for Livin in progression and therapy of cancer. Mol. Cancer Ther. 7: 3661-3669. http://dx.doi.org/10.1158/1535-7163.MCT-08-0480

Yan B (2011). Research progress on Livin protein: an inhibitor of apoptosis. Mol. Cell. Biochem. 357: 39-45. http://dx.doi. org/10.1007/s11010-011-0873-7 